\title{
Towards A Theoretical Integration Of Sustainability: A Literature Review And Suggested Way Forward
}

\author{
Justin Bateh, Florida State College at Jacksonville, USA \\ Donald H. Horner, Jr., Jacksonville University, USA \\ Ardell Broadbent, Pepperdine University, USA \\ David Fish, Florida State College at Jacksonville, USA
}

\begin{abstract}
Organizations worldwide have adopted sustainability strategies to enhance their productivity and develop a competitive advantage. More often than not, organizations and their leaders develop a narrow view of sustainability and consider only the aspects of sustainability that are directly related to their sphere of performance (internal sustainability). Yet, sustainability issues impact all business and non-business organizations, as well as the long-term sustainability of international business relations and quality of life issues worldwide (external sustainability). An increase of appropriate sustainability efforts often requires expanding beyond conventional thinking. Economic necessity can drive both internal and external sustainability measures. Leadership effort is essential to enable shifts in organizational culture that enable sustainability efforts to succeed.
\end{abstract}

This article discusses the sustainability movement. After defining internal and external sustainability, this paper discusses the philosophy of sustainability, internal and external sustainability, measurements, leadership, and best practices.

Keywords: Organizational Sustainability; Leadership; Transparency; Measurements

\section{INTRODUCTION}

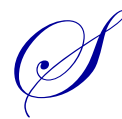

ustainability has many definitions. It might refer to social responsibility, ethics, or a larger piece of the strategic management rubric and has also been tied to strategic decision-making. It also has ties to ecological concerns, the natural environment and, according to Crane and Matten (2004), economic and social concerns (p. 22). The most recent trends in sustainability research are closely associated with the economy and leadership within organizations.

Although sustainability has several different meanings (Bateh, Heaton, Arbogast, \& Broadbent, 2013), its significance in business development and market growth continues to increase. For thousands of consumers, sustainability has become a fundamental measure of organizations' business success and public accountability. In an article focused on defining sustainability in the business setting, it is described as longevity of the organization, maintenance of core principles or purposes, and responsibility to external needs (Bateh et al., 2013). The first two of these principles can be referred to as internal sustainability, while the third can be referred to as external sustainability; both are described below in more detail.

Internal sustainability: As applied to for-profit organizations, internal sustainability is concerned with survival in a competitive market, which increasingly includes global competition. Internal sustainability also relates to maintenance of core principles or purposes as external pressures may necessitate changes in operations and policies (Raatsch, 2012). 
External sustainability: Responsibility to external needs includes more than the provision of products or services to meet a current market demand. It must take into account societal needs that relate to quality of life issues worldwide. For example, the exploitation of labor and natural resources of other nations and the creation of products or by-products that are polluting the ecosystems, are practices that fail to meet the definition of external sustainability. Many organizations still are reluctant to invest financial and human resources in external sustainability initiatives. To reverse this trend, for-profit businesses must move to the forefront of the current sustainability movement.

Businesses are expected to use finite resources in ways that allow enough to remain available to future generations to ensure that their quality of life is not diminished by the current generation's consumption. This is one of the basic challenges faced by contemporary organizations; to achieve a balance of economic profitability, while working toward external sustainability, is not an easy task (Raatsch, 2012). Most often this challenge has been skirted with what Corney (2006) calls the willingness to pay approach in which making a profit entails some amount of burden placed on society in terms of environmental degradation or consumption of finite resources. As the human population has increased exponentially over the past decades, humans have finally begun to face the need for allocating resources wisely and equitably, which has become a societal priority in the eyes of many consumers and leaders.

\section{PHILOSOPHY BEHIND THE SUSTAINABILITY MOVEMENT}

The sustainability movement (hereafter referred to as SM) revolves around four ideas: 1) environmental safety, 2) social responsibility, 3) economic justifications, and 4) perceptual branding. The etiology of the SM grew out of both the environmental and social responsibility movements. Curley and Noormohamed (2014) noted that "corporate social responsibility (CSR) is a trend in corporate policy which serves as a self-regulatory guide to socially and environmentally responsible business practices" (p. 62). The economic benefits include cost-reduction and improved operations. Dey, Laguardia, and Srinivasan (2011) added, "though adding sustainability throughout the organization takes creativity, many firms have learned how to use it to differentiate themselves from their competitors, reduce costs, and improve services to their customers" (para. 3).

Stakeholders at various levels have come to expect organizational sustainability programs, and these programs can generate a great deal of good will (Corner, 2006). Cherneva (2012) echoed this corollary of sustainability and public relations: “...[environmental, social, and governance] ESG factors are treated here as public interest issues that affect human, societal, and environmental well-being and that are increasingly relevant to business and finance operations" (para. 10). Lastly, organizations enjoy marketing their sustainability programs to stakeholders. With the SM continuing to grow, organizations not only market but also tout their SM programs under the umbrella of the "green" movement. Nagar (2014) added that "from the point of view of the companies, however, associating environmental issues with brands is fast becoming one of the ways of gaining competitive advantage" (para. 2).

\section{HOW EFFORTS AIMED AT INTERNAL SUSTAINABILITY ENHANCE EXTERNAL SUSTAINABILITY}

Internal sustainability can be framed as internal resource management. In an expanding economy, companies do well to invest in growth initiatives, and these expenditures often pay off and promote a perception of financial stability. Yet in an arguably contracting economy, many companies narrow their focus to sustainability rather than growth. This entails careful use of resources and reduction of waste. For example, the growing energy costs exemplify one of the major problems affecting today's businesses, and organizations need to evaluate and predict future changes in energy costs (Interdonato, 2012).

Some companies have chosen to cut costs or help employees cut costs in a host of ways, including implementing recycling programs, reducing packaging, using more sustainably-sourced packaging, paperless billing/paychecks and communications, bike-to-work days, showers on site to make biker commutes feasible, providing carpool boards, flex-time allowing employees to avoid rush hour commute, telecommuting, or timerregulated bathroom lights. These types of changes, though potentially needing initial investment, can save costs in 
the long term. While internal sustainability may necessarily serve as the primary concern of for-profit companies, such efforts arguably contribute to both internal and external sustainability.

\section{HOW EFFORTS AIMED AT EXTERNAL SUSTAINABILITY ENHANCE INTERNAL SUSTAINABILITY}

Positive public relations: The economic component of environmental protection and ecological sustainability is increasingly important. Consumer demand has begun to take into account external sustainability. PR campaigns recognize this and promote their organizations as "green" or ecologically conscientious.

Benefits of small independents can trump economies of scale: Often it is difficult to tell whether customers are taking an idealistic "vote-with-the-dollar" or "buy local" stance to support ecologically conscientious practices or products, or whether they are simply acting in self interest in response to their own economic needs. An example is the growing popularity of consumer co-ops, owned and governed collectively by the communities that utilize the goods or services. Such co-ops may derive some success from the popularity of their local and self-governed status from those who value that status from a political perspective. Yet, they also derive popularity from the elements of service-orientation and cost effectiveness, which are facilitated by the local ownership that can respond more rapidly to local needs than franchises or large corporations offering similar goods or services might be authorized to do.

Cost-effectiveness used to be based on economies of scale - a principle that has been capitalized on by companies, such as Walmart, to offer lower prices than were possible for smaller businesses. Yet some small businesses have begun to give stiff competition in low pricing because of their ability to make use of 1) less standardized buildings that reduce start-up costs (i.e., moving into existing structures rather than building new structures); 2) smaller structures that reduce overhead costs (i.e., rent and utilities are often non-existent in farmers markets); 3) convenient neighborhood locations that save travel costs for the customer or client; 4) highly motivated employees who have a stake in the success of the business overall and/or have trust-based relationships with management, giving them a service-orientation that retains customers; and 5) higher satisfaction and retention of employees based on the flexibility afforded them in a less bureaucratized environment. Even if such models are utilized for purely economic reasons, customer loyalty can be enhanced by emphasizing the external sustainability ideals.

\section{LEADERSHIP ROLE IN FOSTERING SUSTAINABILITY}

There is little disagreement that sustainability matters, but one of the key questions is how sustainability initiatives can be successfully implemented. One of the most recent trends is interpreting sustainability implementation in the context of organizational change. Put differently, sustainability initiatives are recognized as complex and challenging as any other organizational change initiatives that are prompted by change in external factors. Implementing a sustainability program also has organizational culture implications which produce accompanying resistance to change. Thus, organizations that consider meeting their sustainability potential must be prepared to overcome major barriers such as employee resistance and eccentricities associated with organizationwide culture change.

According to Lozano (2012), internal sustainability goals must be fully integrated with organizational change efforts. Only through planned organizational change can enterprises move to a sustainably-oriented performance, and only a well-orchestrated organizational change can institutionalize corporate sustainability within organizations (Lozano, 2012). Modern organizations have many different change frameworks to choose from. Through successful implementation of change management processes, organizations can address the needs of all stakeholders and develop a long-standing sustainability mentality at all levels of their organizational structure (Banerjee, 2012). Research suggests that only output-focused change management processes can ensure the success of all sustainability initiatives (Banerjee, 2012). This demands that sustainability measures be developed to determine whether output-focused goals have been met. 


\section{EXISTING SUSTAINABILITY MEASURES}

Reporting is becoming an essential tool for accountability to exhibit and measure sustainability, yet there remains a lack of standard outcome measures that would allow comparison across organizations. This problem is mainly due to the lack of uniform standards for accountability assurance and reporting (Ballou et al., 2012). This section discusses two main formats: 1) internal sustainability audit and accounting processes and 2) use of external guidelines by which to benchmark reporting.

Verschoor (2012) proposes linking sustainability reports with other standard practices of organizational performance, including social and economic ones. Companies will increasingly realize the importance of such integration, leading to the creation of cohesive reporting structures and improving reliability of all organizational reports (Verschoor, 2012). Accountants have not typically been considered crucial to sustainability initiatives, although their involvement could benefit organizations and enhance their sustainability potentials. Regardless of how sustainability is defined, it always involves an economic aspect (D’Aquila, 2012).

It follows that accounting may become an essential ingredient of all sustainability initiatives in organizations, as with triple bottom line accounting (i.e., accounting methods that attempt to include environmental costs rather than treating them as externalities). According to the Yale Center (2013), products, services, and models for such accounting include life cycle assessment, measures of consumption such as the ecological footprint, and measurements of quality of environmental governance such as the Environmental Performance Index (EPI).

The importance of reporting has grown to the point that more than 3,000 organizations around the world publish their sustainability reports, including over $60 \%$ of all Fortune 500 companies (D'Aquila, 2012). Sustainability reporting generally refers to publication of various non-financial factors related to social, environmental, and governance issues, which companies use to improve their accountability and transparency (Borkowski et al., 2012).

The following list briefly describes some of the existing standards for generalized best practices and reporting structures (in alphabetical order):

- $\quad$ The latest European Eco-Management and Audit Scheme Regulation (EMAS III) has been available since 2010. EMAS reports that "the scheme is now globally applicable and includes key performance indicators and a range of further improvements. Currently, more than 4,500 organizations and approximately 7,800 sites are EMAS registered" (European Commission, 2010).

- International Organization for Standardization (ISO) (2013) provides environmental management standards. ISO 14000 provides practical tools for organizations to identify and control their environmental impact to improve their performance, including life cycle analysis, communication strategies, and auditing.

- $\quad$ Framework for Strategic Sustainable Development (FSSD) provides input-output analysis, which can be used for any level of organization with a financial budget. It is grounded in peer-reviewed science and is intended to provide concrete, customized guidelines for how to approach sustainability in a way that improves the bottom line. It also clarifies how to select the most effective sustainability tools for your specific needs and gives the actors in your system a common language and a way to unify their efforts, reconciling short-term with long-term goals and social responsibility (Natural Step, 2012).

- The Sustainability Reporting Framework (SRF) is the set of reporting guidance materials provided by the Global Reporting Initiative (GRI) (GRI, 2013). Development of the framework follows GRI's due process, using GRI's multi-stakeholder international consultation method. Public comment periods, diverse expert working groups, and GRI's approval procedures are meant to ensure that the content of the framework is consensus-based and reflects the broadest possible stakeholder input.

These environmental oversight boards and their products constitute an important development culturally and economically. Similar to regulatory non-profit organizations in many fields, they allow organizations a selfregulating certification mechanism. There are many reasons why these boards may be more efficient and effective than the government oversight that may take its place where self-regulation has not yet been shown to be effective: 
1) these organizations are self-sustaining, running on membership fees and not taxes, 2) they do not get bogged down with inefficiencies that plague bureaucracies, and 3) they are sensitive to consumer feedback.

In citing other researchers, Arevalo et al. (2011) constructed eight reasons why organizations should embrace sustainability measures: 1) sustainability as a method of developing new forms of dialogue among stakeholders (para. 20), 2) sustainability as a method of establishing transparency in company-supplier relations leading to ethical markets (para. 21),3) sustainability as a starting point for integrating bottom-up with top-down decision-making processes (para. 22), 4) sustainability focused on operational integration and routinization [sic] predicated upon total quality management philosophies (para. 23), 5) sustainability as a differentiation strategy (para. 24), 6) sustainability as a narrative in building market credibility, new strategies, and related business activities (para. 25), 7) sustainability leading to varied learning approaches in developing operating and strategic elements as a piece of the sustainability rubric, which leads to a collective "sense-making" process to propel organizational culture (para. 26), and 8) sustainability as a link between policy and organizational culture processes for learning necessary for the success of the business model (para. 27).

If businesses adopt one or more of these standards voluntarily, they lessen the likelihood that their industry will become involuntarily regulated, bringing a host of new costs and burdens. In addition, Potoki and Prakash (2005) insist that adopting standards voluntarily brings a public relations benefit that some competitors will have. At some point, government may do well to mandate that a particular audit system be used in order to level the playing field so that some organizations that have been willing to let others bear their environmental costs will not benefit from a severe underpricing strategy.

\section{AREAS FOR FUTURE RESEARCH}

According to Epstein and Yuthas (2012), few reliable methods exist for assessing the outcomes of sustainability measures. Current trends suggest that internal sustainability will become an integral element of companies' performance reporting and external sustainability will become an important public relations and communications strategy. Reporting is becoming an essential tool of accountability, yet there remains a lack of standard outcome measures that would allow comparison across organizations. Ballou et al. (2012) noted that relatively little is currently known about the nature, scope, and results of various sustainability initiatives developed by organizations worldwide.

A solid basis for future research - in which managers and scholars can engage in a coherent, collaborative effort for the sake of reconciling the existing differences in stakeholder and management assumptions about sustainability performance outcomes - could be assisted by wider use of existing sustainability metrics. Future research might focus on the utilization of comprehensive sustainability reporting guidelines - such as those listed in this article - that will facilitate the integration of sustainability principles with the fundamental strategic values and principal governing organizations.

\section{SUMMARY AND CONCLUSION}

Sustainability is widely accepted as one of the most important factors of organizational growth and development. The body of research on corporate sustainability is increasing. The most relevant sustainability trends are related to organizational leadership, change, and culture, as well as sustainability accounting and reporting. The development of internal sustainability strategies can foster cohesive relationships between businesses and their stakeholders. With profit-based incentives in mind, more resources will be allocated for solutions aimed at internal and external sustainability. This allocation of resources may help create the intellectual capital needed to address problems that previously appeared intractable (Callahan, 2012). Voluntary use of these sustainability reporting structures for both the public and private sectors will further facilitate the integration of sustainability principles with the fundamental values and principles governing organizations. Business leaders should 1) embrace sustainability goals and reporting as a routine part of measuring organizational effectiveness, 2) encourage professional associations to create a single standardized reporting structure and central repository for collection, 3) integrate sustainability initiatives as a part of a successful cost-reduction strategy, and 4) utilize sustainability efforts as an opportunity to create positive public perceptions of corporate social responsibility, thus giving organizations a competitive advantage. 


\section{AUTHOR INFORMATION}

Dr. Justin Bateh is a faculty member in the School of Business at Florida State College at Jacksonville, where he teaches leadership, management, operations, and statistics courses. Prior to entering academia, Dr. Bateh held leadership positions at a private, national medical education firm, including time as the Director of Operations, Associate Director of Production and Fulfillment, Operations Manager, and Research Analyst. Dr. Bateh graduated from the University of North Florida with a Bachelor of Business Administration in Marketing. He also received Master of Business Administration in Management from Nova Southeastern University, and a Doctor of Business Administration in Leadership from Walden University. Dr. Bateh is pursuing further specializations and will soon complete a Graduate Certificate in Applied Statistics from Pennsylvania State University, and is enrolled in the University of Arkansas Master of Science in Operations Management program within the Department of Industrial Engineering, College of Engineering. His research interests involve applying quantitative approaches to issues in leadership and management. E-mail: justin.bateh@ @scj.edu (Corresponding author)

Dr. Donald H. Horner, Jr. is Special Assistant to the President and Professor of Management at the Davis College of Business at Jacksonville University (JU), Jacksonville, Florida. He returned to JU after serving for two years as the City of Jacksonville's first Education Commissioner, a cabinet level appointment in Mayor Alvin Brown's administration. Previously, Horner was the Class of '61 Chair and Distinguished Professor of Leadership Education in the Department of Leadership, Ethics, and Law at the United States Naval Academy, Annapolis, Maryland. A native of Bressler, Pennsylvania, Horner graduated from the United States Military Academy at West Point with a Bachelor of Science degree in General Engineering. He also received an M.S. in Transportation Systems from the Massachusetts Institute of Technology, and an M.A. and Ph.D. in Sociology (organizational theory) from Stanford University. He has taught at Christopher Newport University, Stanford, West Point, Penn State, the University of Maryland, the Naval Academy, the Naval Postgraduate School, and Jacksonville University. He was appointed by Ambassador David Abshire to serve on the Advisory Council of the National Consortium for Character-Based Leadership Education. His research, publications, and consulting practice focus on organizational culture and leadership. E-mail: DHorner3@ju.edu

Ardell Broadbent is a small business owner who is active in non-profit organizations promoting ecological sustainability in local government. She has an MA from Pepperdine University in psychology. She has developed and writes for websites on issues of global ecological change, health, and interpersonal relationships. Ms. Broadbent's areas of interest include education research and cultural change. E-mail: ardell.broadbent@gmail.com

Dr. David Fish is full-time faculty in the School of Business at Florida State College at Jacksonville, Kent Campus where he teaches upper division business courses including finance, leadership, management, and written communication. Prior to joining Florida State College at Jacksonville, Dr. Fish served for over a decade in both single and multi-unit leadership positions in the energy industry in the compresses gases division. Moreover, Dr. Fish owns his own consultancy focusing on providing policy and training uncovering the nuances of workplace violence. Dr. Fish spent his post high-school years with the U.S. Navy Sea, Air, and Land (SEAL) Teams culminating in nearly 14 years of active duty service. Currently, he is an Intelligence Officer with the U.S. Navy Reserve. Dr. Fish holds six post-secondary degrees including an undergraduate degree in Public Administration from National University, four graduate degrees including: Human Resources Management, Management, and Public Administration from National University, and a MBA in Finance from Webster University. He earned a Doctor of Education degree in Organizational Leadership from Nova Southeastern University and is currently enrolled in a Doctor of Philosophy degree in Business, Corporate, and Campus Security at Northcentral University. His current research is focused on various leadership topics. E-mail: $\underline{\text { dfish@ @fscj.edu }}$

\section{REFERENCES}

1. Archibald, J. (2013). Organizational change in the construction industry: Corporate environmentalism and corporate social responsibility. (Unpublished doctoral work). Claremont Graduate University, Claremont, CA. 
2. Arevalo, J. A., Castelló, I., de Colle, S., Lenssen, G., Neumann, K., \& Zollo, M. (2011). Introduction to the special issue: Integrating sustainability in business models. The Journal of Management Development, 30(10), 941-954. doi:http://dx.doi.org/10.1108/02621711111182466

3. Ballou, B., Casey, R. J., Grenier, J. H., \& Heiger, D. L. (2012). Exploring the strategic integration of sustainability initiatives: Opportunities for accounting research. Accounting Horizons, 26(2), 265-288.

4. Banerjee, S. B. (2012). Embedding sustainability across the organization: A critical perspective. Academy of Management Learning \& Education, 10(4), 719-731.

5. Bateh, J., Heaton, C., Arbogast, G. W., \& Broadbent, A. (2013). Defining sustainability in the business setting. American Journal of Business Education, 6(3). Retrieved from http://journals.cluteonline.com/

6. Borkowski, S. C., Welsh, M. J., \& Wentzel, K. (2012). Sustainability reporting at Johnson \& Johnson: A case study using content analysis. International Journal of Business Insights and Transformation, 4(3), 96105 .

7. Callahan, R. F. (2012, Spring). Moving beyond magical thinking: Finding leadership, strategy, and fiscal sustainability in local government. National Civic Review, 8-10.

8. Cherneva, I. (2012). The business case for sustainable finance: Beyond public relations, ethics, and philanthropy. The Fletcher Forum of World Affairs, 36(2), 93-102. Retrieved from http://search.proquest.com.proxy1.ncu.edu/docview/1350918819?accountid=28180

9. Corney, G. (2006). Education for sustainable development: An empirical study of the tensions and challenges faced by geography student teachers. International Research in Geographical and Environmental Education, 15, 224-240. doi:10.2167/irgee194.0

10. Crane, A. \& Matten, D. (2004). Business ethics: A European perspective. Oxford: Oxford University Press.

11. Curley, C. B., \& Noormohamed, N. A. (2014). Social media marketing effects on corporate social responsibility. Journal of Business \& Economics Research (Online), 12(1), 61-n/a. Retrieved from http://search.proquest.com.proxy1.ncu.edu/docview/1477975396?accountid=28180

12. D'Aquila, J. (2012, April). Integrating sustainability into the reporting process and elsewhere. The CPA Journal, 17-24.

13. Dey, A., LaGuardia, P., \& Srinivasan, M. (2011). Building sustainability in logistics operations: A research agenda. Management Research Review, 34(11), 1237-1259. doi: http://dx.doi.org/10.1108/ 01409171111178774

14. European Comission. (2010). EMAS factsheet. Retreived from http://ec.europa.eu/environment/ emas/pdf/factsheet/fs_EMAS2to3.pdf

15. Epstein, M. J., \& Yuthas, K. (2012). Analyzing sustainability impacts. Strategic Finance, $27-33$.

16. Global Reporting Initiative. (2013). About sustainability reporting. Retrieved from www.globalreporting.org

17. Interdonato, D. (2012). Streamlining sustainability: Building information modeling opens numerous avenues for industrial engineers. Industrial Engineer, 41-44.

18. International Organization for Standardization. (2013). ISO 14001 Environmental management systems: An easy-to-use checklist for small business. Retrieved from http://www.iso.org/iso/home/store/ publication_item.htm?pid=PUB100329

19. Lozano, R. (2012). Orchestrating organizational changes for corporate sustainability: Overcoming barriers to change. Greener Management International, 57, 43-64.

20. Nagar, K. (2014). An empirical investigation into the influence of green advertising on brand loyalty. Journal of Services Research, 13(2), 71-94. Retrieved from http://search.proquest.com.proxy1.ncu.edu/ docview/1470782014?accountid=28180

21. Natural Step. (2012). The four system conditions of a sustainable society. Retrieved from http://www.naturalstep.org/en/the-system-conditions

22. Raatzsch, R. (2012). On the notion of sustainability. Inquiry, 55(4), 361-385.

23. Potoski, M., \& Prakash, A. (2005). Green clubs and voluntary governance: ISO 14001 and firms' regulatory compliance. American Journal of Political Science, 49(2), 235. doi:10.1111/j.0092-5853.2005.00120.x

24. Yale Center for Environmental Law \& Policy. (2013). Environmental performance index. Retrieved from http://epi.yale.edu

25. Verschoor, C. C. (2011, December). Should sustainability reporting be integrated? Strategic Finance, 1215 . 


\section{NOTES}

